\title{
Valproic acid-associated low fibrinogen and delayed intracranial hemorrhage: case report and mini literature review
}

This article was published in the following Dove Press journal:

Drug Design, Development and Therapy

12 August 2013

Number of times this article has been viewed

Hai-Fei Chen',2
Li-Ping Xu'
Zhi-Yong Luo'
Zi-Qiang Yu'
Zheng-Yang Li'
Qing-Ya Cui'
Long-Mei Qin'
Yong-Ya Ren'
Hong-Shi Shen'
Jie-Qing Tang'
Ling-Juan Jin'
Jing-Jing Zhu'
Jing Wang'
Ke-Yuan Wang'
Tian-Qin Wu'
Zhao-Yue Wang'
'Department of Hematology,
I00th Hospital of People's Liberation
Army, 'jiangsu Institute of Hematology,
First Affiliated Hospital of Soochow
University, Suzhou, People's
Republic of China

Correspondence: Tian-Qin Wu Department of Hematology, 100th Hospital of People's Liberation Army, Suzhou, 215007, People's Republic of China

Tel +86 05I2 6506354I

Email chhfl224@163.com;

Zhao-Yue Wang

Jiangsu Institute of Hematology, First Affiliated Hospital of Soochow University, Suzhou, 215006, Jiangsu Province,

People's Republic of China,

Tel +860512 67780460

Email zwangI I@sina.com

\begin{abstract}
A 41-year-old male had suffered from gradual hearing loss in his right ear for 2 years. Head computed tomography and magnetic resonance imaging scans showed a neoplasm in the cerebellopontine angle region, which was confirmed by the diagnosis of acoustic neurilemmoma by pathological findings after surgery. Following surgery, he routinely received valproic acid (VPA) to prevent seizures. However, the patient presented with hypofibrinogenemia and cerebral hemorrhage after taking VPA for 12 days. The hypofibrinogenemia recurred when VPA was re-administered. After withdrawal of VPA, his fibrinogen concentration rose to normal within several days. As far as we are aware, this is the first case of cerebral hemorrhage due to VPA to have been reported. Herein, as well as reporting on this case, a mini review of the relevant literature is also presented.
\end{abstract}

Keywords: side effect, hypofibrinogenemia, cerebral hemorrhage, cerebellopontine angle, neoplasm

\section{Introduction}

Valproic acid (VPA) is the main antiepileptic drug broadly administered for all types of seizures. Its excellent efficiency has been shown over four decades of clinical use. Acute toxicity is rare, and when it does occur, it usually follows a benign course. ${ }^{1}$ Fatal hepatic failure is usually seen following chronic use of VPA. ${ }^{2}$ The most commonly reported adverse effects are anorexia, nausea, and vomiting. Less frequently, thrombocytopenia; abnormal platelet function; decreased von Willebrand factor concentration; abnormal bleeding time; and activated partial thromboplastin time (APTT) with decreased fibrinogen (Fbg) levels and prolonged prothrombin time (PT) leading to bruising, petechiae, hematoma, and epistaxis have been reported. ${ }^{3}$ In general, the adverse effects in the hemostatic system are mild or found as abnormal parameters with little clinical significance in laboratory assays. ${ }^{4}$ Here, we report the case of a male patient with hypofibrinogenemia and cerebral hemorrhage during treatment with oral VPA.

\section{Case presentation}

A 41-year-old male had suffered from gradual hearing loss in his right ear for 2 years. Head computed tomography and magnetic resonance imaging scans showed a neoplasm in the cerebellopontine angle region, which was suspected to be acoustic neurilemmoma. Preoperative routine coagulation tests of APTT, PT, thrombin time, Fbg, and platelet count (Plt) were within the normal ranges, and he had no history of bleeding since birth. Clinical examination, biochemistry analysis, and kidney function were normal. The echocardiogram showed normal sinus rhythm. The patient had a 
history of hepatitis B 20 years before; however, liver enzymes and synthesis function were normal before surgery.

Resection of the neoplasm was successfully performed and blood loss was not excessive during the operation. The results of the pathological examination confirmed the diagnosis of acoustic neurilemmoma. VPA was administered at $20 \mathrm{mg} / \mathrm{kg} /$ day to prevent seizures after surgery. Twelve days after surgery, the patient reported headache and examination suggested suspected re-bleeding from the surgical site. This was confirmed in the second surgery. He was treated by decompressive craniotomy to relieve the high pressure.

After the second surgery, a drainage tube was inserted in the incision, since interim bleeding was present (Figure 1). He received daily transfusions of fresh plasma and cryoprecipitate to improve coagulation function, but the volume of drainage from surgical lesions remained about $30 \mathrm{~mL} / \mathrm{d}$. His coagulation function was again tested and he was found to have normal PT, APTT, TT, D-dimer, coagulation factors, and Plt, but a low Fbg level (0.8-1.6 g/L; reference value, 2-4 g/L), high tissue-type plasminogen activator (t-PA) activity $(5,400 \mathrm{U} / \mathrm{mL}$; reference value, 300-600 U/mL), and high fibrinogen/fibrin degradation product (FDP) level (60 mg/L; reference value, $<10 \mathrm{mg} / \mathrm{L}$ ). Meanwhile, his biochemistry results, kidney function, and liver function remained normal.

The patient was referred to the Department of Hematology for further management on 30 days following his first surgery. With a supplement of daily Fbg ( $3 \mathrm{~g} / \mathrm{d})$ and use of antifibrinolytic agents for 5 days, the amount of bleeding from

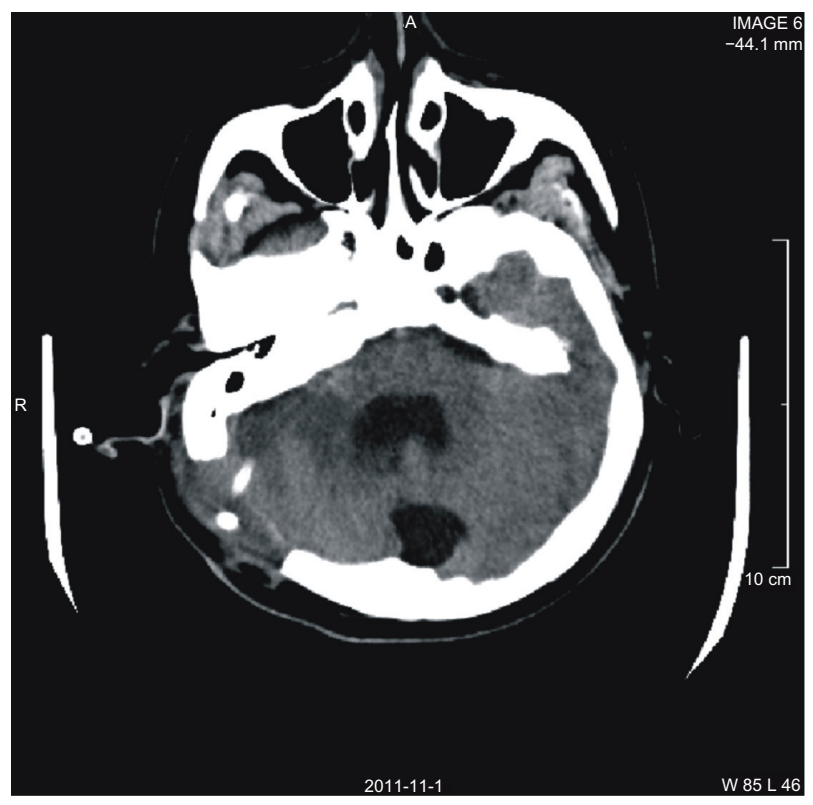

Figure I Image after second surgery. Head CT axial image shows the drainage tube placed in the lesion.

Abbreviation: CT, computed tomography. the drainage tube decreased gradually and the patient felt his headache relieved without VPA. Coagulation was tested daily and results showed that the Fbg gradually returned to normal within 5 days: from $0.8 \mathrm{~g} / \mathrm{L}$ on the first day to $1.2 \mathrm{~g} / \mathrm{L}$ on the second day of treatment, $1.8 \mathrm{~g} / \mathrm{L}$ on the third day, $2.3 \mathrm{~g} / \mathrm{L}$ on the fourth day, and $3.5 \mathrm{~g} / \mathrm{L}$ on the fifth. Coagulation parameters were maintained at normal levels in a week without Fbg transfusion.

Following this, the patient was referred again to the Department of Neurosurgery and VPA treatment was resumed. Amazingly, his Fbg level decreased over time, reaching the minimum level of $0.53 \mathrm{~g} / \mathrm{L}$ on the fifth day of VPA re-administration. Fortunately, the patient had no bleeding symptoms or manifestation. VPA-associated hypofibrinogenemia was suspected, so the treatment discontinued. Following this, his Fbg level returned to normal and remained stable. The drainage tube was removed 61 days after his first surgery. At follow-up at 6 months, the patient's hemostatic parameters including Fbg were normal and no symptoms of bleeding were found.

\section{Discussion and mini literature review}

The patient presented with hypofibrinogenemia and cerebral bleeding 12 days after taking the recommended dosage of VPA. His bleeding was alleviated as plasma Fbg concentration returned to normal after discontinuing VPA. This suggests a causal relationship between the hypofibrinogenemia, cerebral bleeding, and administration of VPA. Interestingly, this phenomenon recurred on re-administration of the VPA, confirmed by this second use and subsequent discontinuance of the treatment.

VPA was approved by the US Food and Drug Administration in 1978 and is indicated for all seizures including complex partial seizures, simple and complex seizures. ${ }^{5,6}$ Therefore, it is extensively prescribed as an antiepileptic drug to prevent seizures in patients after neurological surgery. Although VPA-associated coagulopathies are common, significant clinical bleeding complications are rare. ${ }^{4}$

Fbg, a soluble plasma glycoprotein synthesized by the liver, is converted by thrombin into fibrin during blood coagulation. Congenital deficiency or abnormal function of Fbg was ruled out in this patient, as he had no personal or family history of bleeding, and the results of his preoperative coagulation tests were normal. Therefore, his hypofibrinogenemia during oral VPA administration was acquired. As is well known, acquired deficiency comprises primary and secondary fibrinolysis. However, in this case, the latter (disseminated 
Table I Literature on valproic acid (VPA)-associated hypofibrinogenemia

\begin{tabular}{|c|c|c|c|c|c|c|c|}
\hline Study & Year & Research type & $\begin{array}{l}\text { Hypofibrinogenemia } \\
\text { patients, } n / N\end{array}$ & $\begin{array}{l}\text { VPA dose, } \\
\mathrm{mg} / \mathrm{kg} / \mathrm{d}^{*}\end{array}$ & $\begin{array}{l}\text { Mean level } \\
\text { of Fbg, } \\
\text { g/L (nadir) }\end{array}$ & $\begin{array}{l}\text { Hypofibrinogenemia- } \\
\text { associated clinical } \\
\text { bleeding }\end{array}$ & $\begin{array}{l}\text { Discontinuation } \\
\text { of therapy }\end{array}$ \\
\hline Serdaroglu ${ }^{14}$ & 2002 & Retrospective & $8 / 29$ & $20-30$ & $2.40(1.39)$ & No & No \\
\hline Gerstner ${ }^{4}$ & 2006 & Retrospective & $5 / 385$ & $20-130 \mathrm{mg} / \mathrm{mL}^{\mathrm{a}}$ & NA & No & Nob \\
\hline Anderson 15 & 2003 & Prospective & $0 / 75$ & $40-100 \mathrm{mg} / \mathrm{mL}^{\mathrm{a}}$ & NA & No & No \\
\hline Tokuda $^{16}$ & 1994 & Retrospective & $3 / 3$ & $59.7 \mathrm{mg} / \mathrm{mL}^{\mathrm{a}, \mathrm{c}}$ & $0.46(0.22)$ & No & NA \\
\hline Hauser ${ }^{17}$ & 1996 & Prospective & $\mathrm{NA} / 50$ & $20-27$ & $1.92(0.76)$ & No & NA \\
\hline Koenig10 & 2008 & Prospective & $12 / 23$ & $70-120 \mathrm{mg} / \mathrm{mL}^{\mathrm{a}}$ & I.5I (NA) & No & No \\
\hline $\mathrm{Köse}^{12}$ & 2009 & Prospective & $2 / 24$ & $20^{\mathrm{d}}$ & $1.89(0.88)$ & No & No \\
\hline Eberl ${ }^{18}$ & 2009 & Prospective & $9 / 40$ & NA & 2.22 (NA) & No & No \\
\hline Topf ${ }^{19}$ & 2011 & Comparison study & $\mathrm{NA} / 40$ & NA & $N A^{e}$ & No & No \\
\hline
\end{tabular}

Notes: *Unless otherwise indicated. aSerum level of; 'bfibrinogen increased after VPA dosage reduction or discontinuation; 'combination of ACTH-Zn (adrenocorticotrophinzinc phosphate) and VPA; ${ }^{d}$ started at dose of $10 \mathrm{mg} / \mathrm{kg} / \mathrm{d}$ (a week later the dose was raised to target dose); ${ }^{\mathrm{e}}$ patients in the VPA group had lower hypofibrinogenemia than those in the control group $(P<0.05)$.

Abbreviations: Fbg, fibrinogen; NA, not available.

intravascular coagulation) was easily precluded because the patient had normal Plt count and TT during the course. Thus, the patient's low Fbg concentration could have resulted from acquired/primary fibrinolysis or synthesis deficiency. The normal liver function during the disease indicated the normal synthesis function of liver. Therefore, the cause of his low Fbg level was probably primary fibrinolysis.

Since the 1970s, several studies have documented a VPA dose-related decrease in Fbg (mean 1.76 g/L; normal, 1.80 $4.00 \mathrm{~g} / \mathrm{L}){ }^{7,8} \mathrm{In}$ these studies, patients taking other antiepileptic drugs had mean Fbg levels of 2.35-2.72 g/L. One patient taking VPA had their Fbg values decline from 2.10 to $1.25 \mathrm{~g} / \mathrm{L}$. After withdrawal of VPA, Fbg rose to $2.90 \mathrm{~g} / \mathrm{L}$ in 12 days. ${ }^{9}$ In three VPA-treated patients with low Fbg, fibrin degradation products were normal. ${ }^{8}$ Koenig et a ${ }^{10}{ }^{10}$ reported that Fbg levels dropped below the lower limit in 12 out of 23 patients who received VPA therapy. Blood coagulation disturbances are common in patients with VPA, but rarely become clinically symptomatic. Ward et $\mathrm{a}^{11}$ reported similar results. In a prospective study, Köse et a $1^{12}$ reported that VPA causes decreased factor VII levels, Plt, factor VIII, Protein C, Fbg, and increased lipoprotein (a) levels. However, no serious bleeding complications were observed in the studies and no correlation was found between Fbg concentration and the dose, blood level, or duration of VPA therapy in the majority of studies (Table 1).

The striking elevation of fibrin degradation products in our patient suggested his hypofibrinogenemia was a consequence of excessive consumption rather than deficient production. Although most VPA-associated side effects are mild, we propose that in the case of planned surgery or accidents, routine screening tests comprising Plt, PT, and APTT may not be sufficient. Thus, thromboelastography, von Willebrand factor, and ristocetin cofactor should also be tested to treat the defects properly.
To our knowledge, this is the first case of hypofibrinogenemia and cerebral hemorrhage due to VPA treatment that has been reported. The shorter duration of VPA administration and faster recovery of Fbg level may be why the patient had no bleeding during the second oral VPA administration. The longer time from the brain surgery to the second onset of hypofibrinogenemia may also be partially responsible. The precise mechanisms of VPA-associated low Fbg concentration remain unknown. Recently, Larsson et $a{ }^{13}$ reported that VPA induces t-PA expression in cultured endothelial cells and this is associated with increased histone acetylation at the t-PA gene promoter. Their results showed that VPA dosedependently stimulated t-PA mRNA and that protein expression in endothelial cells could reach a two- to fourfold increase at clinically relevant concentrations and tenfold increase at maximal concentrations. This could account for the low level of Fbg in patients who receive VPA treatment.

\section{Disclosure}

The authors declare no conflicts of interest in this work.

\section{References}

1. Chateauvieux S, Morceau F, Dicato M, Diederich M. Molecular and therapeutic potential and toxicity of valproic acid. J Biomed Biotechnol. Epub July 29, 2010

2. Bryant AE 3rd, Dreifuss FE. Valproic acid hepatic fatalities. III. US experience since 1986. Neurology. 1996;46(2):465-469.

3. Gerstner T, Buesing D, Longin E, et al. Valproic acid induced encephalopathy - 19 new cases in Germany from 1994 to 2003 - a side effect associated to VPA-therapy not only in young children. Seizure. 2006;15(6):443-448.

4. Gerstner T, Teich M, Bell N, et al. Valproate-associated coagulopathies are frequent and variable in children. Epilepsia. 2006;47(7): 1136-1143

5. Davis R, Peters DH, McTavish D. Valproic acid. A reappraisal of its pharmacological properties and clinical efficacy in epilepsy. Drugs. 1994;47(2):332-372.

6. Guerrini R. Valproate as a mainstay of therapy for pediatric epilepsy. Paediatr Drugs. 2006;8(2):113-129. 
7. Sussman NM, McLain LW Jr, Leppick IE. Hepatotoxicity of valproic acid. Neurology. 1979;29(4):601.

8. Ojemann LM, Wilensky AJ, Temkin NR, Lovely MP. Fibrinogen and valproic acid. Epilepsia. 1981;22:242-243.

9. Dale BM, Purdie GH, Rischbieth RH. Fibrinogen depletion with sodium valproate. Lancet. 1978;1(8077):1316-1317.

10. Koenig S, Gerstner T, Keller A, Teich M, Longin E, Dempfle CE. High incidence of valproate-induced coagulation disorders in children receiving valproic acid: a prospective study. Blood Coagul Fibrinolysis. 2008;19(5):375-382.

11. Ward MM, Barbaro NM, Laxer KD, Rampil IJ. Preoperative valproate administration does not increase blood loss during temporal lobectomy. Epilepsia. 1996;37(1):98-101.

12. Köse G, Arhan E, Unal B, Ozaydin E, Guven A, Sayli TR. Valproateassociated coagulopathies in children during short-term treatment. J Child Neurol. 2009;24(12):1493-1498.

13. Larsson P, Ulfhammer E, Magnusson M, et al. Role of histone acetylation in the stimulatory effect of valproic acid on vascular endothelial tissue-type plasminogen activator expression. PLoS One. 2012;7(2): e31573.
14. Serdaroglu G, Tütüncüoglu S, Kavakli K, Tekgül H. Coagulation abnormalities and acquired von Willebrand's disease type 1 in children receiving valproic acid. J Child Neurol. 2002;17(1):41-43.

15. Anderson GD, Temkin NR, Chandler WL, Winn HR. Effect of valproate on hemostatic function in patients with traumatic brain injury. Epilepsy Res. 2003;57(2-3):111-119.

16. Tokuda K, Kodani N, Ogino T. Three cases of hypofibrinogenemia induced by chemotherapy with a combination of synthetic ACTH and valproic acid. No To Hattatsu. 1994;26(1):50-56. Japanese.

17. Hauser E, Seidl R, Freilinger M, Male C, Herkner K. Hematologic manifestations and impaired liver synthetic function during valproate monotherapy. Brain Dev. 1996;18(2):105-109.

18. Eberl W, Budde U, Bentele K, et al. Acquired von Willebrand syndrome as side effect of valproic acid therapy in children is rare. Hamostaseologie. 2009;29(2):137-142.

19. Topf HG, Lischetzki G, Trollmann R, Rascher W, Rauh M. The effect of valproate therapy on thrombin generation determined by calibrated automated thrombography. Klin Padiatr. 2011;223(3):165-168.
Drug Design, Development and Therapy

\section{Publish your work in this journal}

Drug Design, Development and Therapy is an international, peerreviewed open-access journal that spans the spectrum of drug design and development through to clinical applications. Clinical outcomes, patient safety, and programs for the development and effective, safe, and sustained use of medicines are a feature of the journal, which

\section{Dovepress}

has also been accepted for indexing on PubMed Central. The manuscript management system is completely online and includes a very quick and fair peer-review system, which is all easy to use. Visit http://www.dovepress.com/testimonials.php to read real quotes from published authors.

Submit your manuscript here: http://www.dovepress.com/drug-design-development-and-therapy-journal 